\title{
PENILAIAN RISIKO KECELAKAAN KERJA PADA PENGOPERASIAN CC (CONTAINER CRANE) DI PT X SURABAYA
}

\author{
Nyco Nugroho \\ PT. Wijaya Karya Gedung, Tbk \\ Jalan Let. Jend. M.T. Haryono, Jakarta Selatan, Daerah Khusus Ibukota Jakarta \\ Email: nyco17nugroho@gmail.com
}

\begin{abstract}
The operation of CC has a high risk accident, in 2013 there are 57 CC operation accidents at PT X. Accident high PC operations require companies to prevent and reduce the risk of accidents at the company, according Act No. 1 Year 1970 Article 3, paragraph 1. Reduce and prevent the risk of workplace accidents by conducting a risk assessment. This study aims to assess the risk.The design of this study was observational with crossectional approach. The main aim of this study was to assessed of risk on CC operate in PT X Surabaya. The subject in this study were safety officer maintenance, technician and CC operator. The object in this study was CC unit. The data were collected by means of observation and interview, while the secondary data from the operation of the CC documents related accidents. The data obtained were analyzed descriptively by tabulations and narration which of compared with the standard ISO 31000: 2009 as well as the existing theories. The results of this study show that there were 4 process of work that has 9 cause danger of accident, 2 causes of accident with the high risk, 5 moderate risk and 2 low risk. Risk control that has done are engineering, administrative, and PPE. From the result of this study, it is recommended that the company provide to implement the work according to SOP, conduct load test and check the condition of the lift on the entire CC, check and repair functions anemometer and sirens on CC, give emergency drill evenly for workers.
\end{abstract}

Keywords: accident risk assessment, Container Crane (CC)

\begin{abstract}
ABSTRAK
Pengoperasian CC memiliki risiko kecelakaan yang tinggi, diketahui pada tahun 2013 terdapat 57 kecelakaan pada PT $X$. Kecelakaan yang tinggi mewajibkan perusahaan untuk mencegah dan mengurangi risiko kecelakaan di perusahaan, sesuai Undang-Undang No. 1 Tahun 1970 Pasal 3 ayat 1, yaitu mengurangi dan mencegah risiko kecelakaan kerja dengan melakukan penilaian risiko. Penelitian ini bertujuan melakukan penilaian risiko kecelakaan pada proses bongkar muat petikemas di dermaga internasional PT X Surabaya. Penelitian menggunakan metode deskriptif observasional dengan objek penelitian unit CC dan subjek penelitian adalah safety officer, teknisi maintenance dan operator CC. Data primer diperoleh dari observasi dan wawancara dan data sekunder diperoleh dari dokumen kecelakaan pengoperasian CC. Data dianalisis secara diskriptif dengan tabel dibandingkan dengan standar ISO 31000:2009 serta teori yang ada. Hasil penelitian diketahui terdapat 4 proses pekerjaan yang memiliki 9 penyebab bahaya kecelakaan, 2 dengan risiko tinggi, 5 dengan risiko sedang dan 2 dengan risiko rendah. Pengendalian risiko yang dilakukan yaitu teknis, administrasi dan alat APD. Perusahaan disarankan mengimplementasikan pekerjaan sesuai SOP, dilakukan load test dan pengecekan kondisi lift pada $\mathrm{CC}$, anemometer dan sirine pada alat CC, emergency drill merata pada seluruh operator CC tiap 3 bulan.
\end{abstract}

Kata kunci: penilaian risiko kecelakaan, Container Crane

\section{PENDAHULUAN}

Pelabuhan merupakan tempat kerja yang aktivitasnya sebagai jalur transportasi laut, tidak hanya manusia tetapi juga angkutan barang. Petikemas merupakan fasilitas yang diberikan oleh penyedia jasa angkutan barang melalui laut, guna menjaga kualitas barang tetap dalam kondisi baik dan mudah diangkut. Bongkar muat petikemas dilakukan dengan menggunakan alat crane sebagai alat angkut. Peralatan angkut menurut Permenakertans RI No.Per.05/MEN/1985 yaitu alat yang dikonstruksi atau dibuat khusus untuk mengangkat naik dan menurunkan muatan. Setiap tempat kerja Setiap tempat kerja selalu mengandung berbagai potensi bahaya yang dapat menyebabkan timbulnya penyakit akibat kerja maupun kecelakaan kerja.

Kecelakaan kerja di Indonesia pada triwulan ke IV pada tahun 2014 diketahui 14.519 kasus kecelakaan kerja. Di Jawa Timur menurut sumber kecelakaannya terdapat 6.725 kecelakaan kerja. Menurut sumber kecelakaannya, kecelakaan akibat 
pesawat angkat angkut sebesar 237 kasus kecelakaan kerja. (Pusdatinaker, 2014). Kecelakaan kerja yang tinggi dapat disebabkan dari faktor manusia maupun peralatan kerja yang digunakan oleh pekerja.

Suma mur (2009), berpendapat risiko kecelakaan dapat terjadi utamanya disebabkan dari tindakan tidak aman maupun kondisi tidak aman. Kondisi tidak aman merupakan kondisi fisik (peralatan, mesin, sifat dan cara kerja) yang dapat langsung mengakibatkan kecelakaan. Tindakan tidak aman merupakan perbuatan dari manusia (kurang pengetahuan, sikap dan tingkah laku yang tidak aman, ketelitian) yang dapat langsung mengakibatkan kecelakaan.

Kecelakaan kerja bersumber dari HSE Center Indonesia (2014) yang terjadi di Kuningan, Jakarta. Tiang penyangga crane patah lalu jatuh menimpa 2 orang pekerja dan beberapa sepeda motor di sekitarnya. Kecelakaan yang terjadi karena kondisi peralatan yang tidak aman. Kecelakaan dapat dihindari apabila pengawasan terhadap kondisi crane dapat dilakukan.

Risiko kecelakaan lain bisa terjadi pada aktivitas bongkar muat petikemas seperti cacat hingga kematian akibat kejatuhan peralatan angkut atau petikemas, kerusakan alat angkut, kerusakan petikemas hingga terhentinya proses produksi. Kecelakaan terjadi di Pelabuhan Rakyat Kalimas Pelabuhan Tanjung Perak Surabaya. Kecelakaan mengakibatkan tenaga kerja meninggal, kerusakan alat angkut hingga terhentinya proses produksi. Kecelakaan bermula tali baja (sling) putus mengakibatkan dua kuli angkut meninggal tertimpa batang crane dan (hook) besi pengait (Wahyudiyanta, 2012).

Kerugian akibat kecelakaan tidak hanya korban jiwa melainkan juga harta benda yang diderita oleh perusahaan. Kecelakaan terjadi pada terminal petikemas di Southampton, satu operator crane kritis akibat rubuhnya crane. Rubuhnya crane merupakan kecelakaan kali kedua yang terjadi, kejadian yang pertama tidak sampai memakan korban jiwa tetapi akibat dari itu perusahaan ditutup selama tiga bulan (Kennedy, 2009).

Kecelakaan diatas diperkuat dengan data kejadian kecelakaan di PT X pada tahun 2013. Diketahui pada tahun 2013 terjadi 57 kaskus kecelakaan container crane. Kecelakaan yang terjadi yaitu handling container on deck, handling container under deck, handling hatch, handling containers from land to ship, violation of work procedures, poor maintenance.
Besar risiko kecelakaan kerja yang diakibatkan dari aktivitas bongkar muat, baik hilangnya nyawa hingga biaya yang dikeluarkan oleh perusahaan untuk perbaikan peralatan. Dibutuhkan pencegahan kecelakaan sebagai penyelengaraan keselamatan dan kesehatan kerja di tempat kerja sesuai UU No. 1/1970 Tentang Keselamatan Kerja. Serta persyaratan pengoperasian alat angkut diatur dalam Permenakertrans RI No.Per.05/MEN/1985 Tentang pesawat angkat dan angkut.

Menurut Tarwaka (2008) pencegahan kecelakaan kerja merupakan upaya untuk mencari penyebab suatu kecelakaan, dengan mengetahui dan mengenal penyebab kecelakaan. Mengetahui dan mengenal penyebab kecelakaan dengan mengidentifikasi bahaya pada suatu pekerjaan dilakukan dengan membagi pekerjaan menjadi langkah-langkah kerja dari awal pekerjaan hingga selesai. (Harjono. 2014). Usaha untuk pencegahan kecelakaan kerja pada pengoperasian $\mathrm{CC}$, perusahaan perlu melakukan penilaian risiko pada aktivitas kerja operator CC.

\section{METODE}

Tujuan dari penelitian ini yaitu melakukan penilaian risiko kecelakaan pada proses bongkar muat petikemas di dermaga internasional PT X Surabaya. Penelitian ini berdasarkan sifat dan sistem analisisnya, bersifat deskriptif observasional dengan pendekatan cross sectional. Objek penelitian yaitu Alat CC (Container Crane) yang ada di dermaga. Subjek penelitian yaitu seluruh operator $\mathrm{CC}$ yang berjumlah 17 orang, Supervisor bongkar muat berjumlah 3 orang, safety officer berjumlah 1 orang dan leader teknisi maintenance CC berjumlah 1 orang.

Variabel yang diteliti dalam penelitian ini adalah bahaya terkait kecelakaan kerja pengoperasian $\mathrm{CC}$ dengan melakukan observasi dan wawancara aktivitas pekerjaan dengan lembar Job Safety Analysis (JSA). Setelah data terkumpul dilakukan penilaian risiko, dengan menentukan likelihood dan severity pada proses pekerjaan operator $\mathrm{CC}$ sesuai standar ISO 31000:2009 pada tabel 1.

Data tingkat risiko yang didapat dianalisis secara diskriptif dengan menjabarkan hasil temuan di lapangan dalam bentuk narasi dan tabel sesuai standart ISO 31000:2009. Setiap bahaya pada pengoperasian CC diidentifikasi juga upaya pengendalian yang dilakukan oleh perusahaan, sesuai dengan hirarki pengendalian yaitu eliminasi, subtitusi, rekayasa teknik, administrasi dan APD. 
Tabel 1. Penilaian Tingkat Risiko

\begin{tabular}{|c|c|c|c|c|c|c|}
\hline \multicolumn{7}{|c|}{ Tingkat Keparahan } \\
\hline \multirow{6}{*}{ 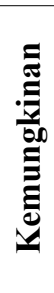 } & & (1) Catastropic & (2) Major & (3) Moderate & (4) Minor & (5) Insignificant \\
\hline & (1) Catastropic & 1 & 2 & 3 & 4 & 5 \\
\hline & (2) Often & 2 & 4 & 6 & 8 & 10 \\
\hline & (3) Sometimes & 3 & 6 & 9 & 12 & 15 \\
\hline & (4) Minor & 4 & 8 & 12 & 16 & 20 \\
\hline & (5) Highly Unlikely & 5 & 10 & 15 & 20 & 25 \\
\hline & High risk & & & & & \\
\hline & 7-15 Medium risk & & & & & \\
\hline & 16-25 Low risk & & & & & \\
\hline
\end{tabular}

Sumber: ISO 31000 (2009)

\section{HASIL}

PT X merupakan terminal petikemas bertaraf internasional pertama di Surabaya, dengan memiliki 2 dermaga yaitu dermaga internasional dan dermaga domestik. Dermaga internasional sepanjang 1.000 meter dengan kedalaman 10,5 meter dan dermaga domestik sepanjang 450 meter dengan kedalaman 7,4 meter. Dermaga yang ada pada PT X dilengkapi dengan 7 unit CC (Container Crane) yang berada pada dermaga Internasional dan 3 unit CC (Container Crane) yang berada pada dermaga domestik. Selain itu juga terdapat lapangan penumpukan petikemas dengan luas 38 Ha. Lapangan penumpukan petikemas dibedakan menjadi 2 yaitu lapangan petikemas internasional dan lapangan petikemas domestik. Lapangan petikemas internasional memiliki luas area $29 \mathrm{Ha}$ dengan kapasitas 21.989 teus, sedangkan domestik memiliki luas area $9 \mathrm{Ha}$ dengan kapasitas 2.435 teus.

Bidang usaha dan jasa pelayanan pada PT $\mathrm{X}$ yaitu pelayanan jasa tambat kapal petikemas, pelayanan jasa bongkar muat petikemas, pelayanan penumpukan petikemas ekspor, pelayanan pengiriman petikemas impor, pelayanan penyediaan air tawar ke kapal, pelayanan penanganan petikemas berpendingin, pelayanan pergudangan pelayanan rel kereta api, pelayanan penyimpanan berpendingin.

Tenaga Kerja pada PT X dibedakan menjadi 2 area lokasi kerja yaitu dermaga dan lapangan penumpukan. Tenaga kerja yang bekerja di PT X sebagian besar merupakan mitra kerja. Tenaga kerja dibedakan antara pekerja shift dan non shift. Pekerja non shift untuk jam kerja operasional hari senin- jumat dengan libur sabtu dan minggu, sedangkan pekerja shift 1 hari secara bergiliran.

Bongkar muat petikemas di PT X menggunakan alat crane, ada 2 jenis crane yang digunakan yaitu CC (Container Crane) dan RTG (Rubber Tyred Gantry). Pengoperasian CC digunakan untuk melakukan bongkar muat petikemas di area dermaga. Bongkar muat petikemas di dermaga, dilakukan untuk mengangkut petikemas dari kapal menuju truck container maupun sebaliknya.

CC yang ada pada area dermaga internasional berjumlah 7 unit, dengan tinggi 40 meter. Ruang operator berada pada ketinggian 25 meter, untuk dapat sampai ke ruang operator terdapat 2 akses yaitu lift dan tangga. Tangga diperuntukkan apabila terjadi keadaan emergency pada saat aktivitas bongkar muat. CC dioperasikan oleh operator yang sudah memiliki SIO (Surat Ijin Operasional) penggunaan crane.

SIO pada operator CC di urus dan diberikan oleh pihak perusahaan. SIO pada operator CC diberikan kepada calon operator yang lolos seleksi persyaratan administrasi, kemudian diikutkan untuk pengurusan SIO operator. SIO pada operator nantinya menjadi jaminan operator untuk kerja di sana, sehingga operator tidak bisa seenaknya untuk keluar dari pekerjaan.

Operator hanya diberikan foto copy SIO, sebagai pegangan operator. Memperpanjang SIO 5 tahun sekali, operator akan diingatkan oleh pihak perusahaan untuk menyerahkan persyaratan administrasi yang diperlukan.

Pelayanan bongkar muat petikemas dilakukan 24 jam, sehingga untuk pengoperasian CC memungkinkan untuk beroperasi setiap hari. 1 
hari kerja dibagi menjadi 3 shift yaitu shift I pukul 00.00-08.00, shift II pukul 08.00-16.00 dan shift III pukul 16.00-00.00 WIB. Jumlah operator CC pada PT X berjumlah 74 orang, dengan 17-18 operator tiap shift.

Tahapan proses pekerjaan pada pengoperasian alat $\mathrm{CC}$ ada 5 yaitu naik atau turun menggunakan anak tangga, naik atau turun menggunakan lift, naik ke ruang operator dan pengoperasian CC. Tahapan pertama yang dilakukan oleh operator yaitu menaiki atau menuruni anak tangga.

Alat CC memiliki tinggi 35 meter dengan lebar 15-20 meter. Alat CC dikendalikan oleh manusia, ruang kendali operator berada pada ketinggian 25 meter. Untuk mengoperasikan alat CC, operator harus menggunakan anak tangga sebelum menggunakan lift untuk naik menuju ruang operator. Anak tangga memiliki tinggi 1 meter, sebelum sampai pintu masuk lift.

Tahapan kedua yang dilakukan oleh operator yaitu naik atau turun menggunakan akses lift. Lift pada alat CC memiliki tinggi 2 meter dengan lebar 1 meter. Lift yang digunakan memiliki kapasitas 150 $\mathrm{kg}$. Untuk bergerak naik atau turun harus menekan terus tombol panah naik atau turun hingga lokasi yang dituju.

Tahapan yang ketiga yaitu, memasuki ruang operator. Jarak lift dengan ruang operator sekitar 8-10 meter, karena posisi cabin operator berada pada tengah-tengah alat. Operator CC harus melewati tangga dan membuka limit swift untuk mencapai ruang operator. Limit swift merupakan safety device pada area cabin operator agar cabin tidak bergerak saat tidak dioperasikan dan tidak dilakukan penguncian pada cabin setelah digunakan. Bentuk limit swift menyerupai pagar yang cara membukanya di angkat ke atas.

Proses yang keempat yaitu pengoperasian alat $\mathrm{CC}$, pengoperasian dengan menggerakkan alat $\mathrm{CC}$ mengangkat dan menurunkan petikemas dari dermaga ke chassis truck. Alat CC memiliki komponen yaitu motor boom, motor gantry dan spreader. Boom merupakan ban berjalan yang memiliki panjang mencapai 15-20 meter digunakan untuk menggerakkan spreader maju atau pin mundur secara horizontal.

Boom ini berfungsi menjangkau letak petikemas terjauh pada kapal dari area dermaga. Spreader merupakan alat yang digunakan untuk mengangkat dan menurunkan petikemas. Motor spreader terdapat flipper yang berfungsi sebagai pengunci petikemas agar dapat diangkat.
Komponen selanjutnya yaitu motor gantry, alat ini merupakan roda yang berada pada keempat kaki dari alat CC. Identifikasi bahaya yang dilakukan dengan melihat risiko kecelakaan dan penyebab kecelakaan pada setiap uraian pekerjaan pada pengoperasian alat CC. Hasil identifikasi bahaya dengan mengamati risiko kecelakaan dan penyebab kecelakaan pada operator $\mathrm{CC}$ mulai dari naik tangga hingga pengoperasian alat $\mathrm{CC}$.

Identifikasi bahaya selesai dilakukan, diketahui risiko kecelakaan dan penyebab kecelakaan pada setiap uraian pekerjaan pada pengoperasian alat CC. Setelah itu dilakukan penilaian risiko kecelakaan untuk menganalisis kemungkinan kejadian (likelihood) dan keparahan kejadian (consequences) dari uraian pekerjaan pada pengoperasian alat CC.

Fungsi motor gantry untuk menggerakkan keseluruhan komponen dalam alat CC secara horizontal ke kanan maupun ke kiri. Sesuai Undangundang nomor 1 Tahun 1970 tentang Keselamatan Kerja pada pasal 3 ayat 1 "Dengan peraturan perundangan ditetapkan syarat-syarat keselamatan kerja untuk mencegah dan mengurangi kecelakaan". Mengacu pada peraturan tentang keselamatan kerja. Penilaian risiko kecelakaan pada pekerjaan operator $\mathrm{CC}$, merupakan salah satu tindakan pencegahan untuk mengurangi risiko kecelakaan pada pekerjaan operator.

Nilai likelihood dan consequences menggunakan standar ISO 31000:2009. Nilai likelihood dan consequences ditentukan dari hasil observasi yang dilakukan, serta didukung dari data kecelakaan yang terkait dengan aktivitas operator CC. Nilai ditetapkan dengan melakukan diskusi terkait hasil observasi dengan safety officer pada PT X.

Nilai likelihood dan consequences yang sudah ditetapkan dengan melakukan diskusi dengan safety officer, dilakukan perkalian untuk mendapat nilai risiko kecelakaan. Nilai risiko kecelakaan yang didapat menunjukkan tingkat risiko yang diterima pada tiap aktivitas pekerjaan yang dilakukan oleh operator CC.

Nilai risiko yang diterima pada tahapan pekerjaan operator $\mathrm{CC}$, dianalisis pengendalian yang ada sesuai hirarki pengendalian. Hirarki pengendalian yaitu Eliminasi, subtitusi, pengendalian teknik, pengendalian administratif dan pengendalian pada manusia yaitu APD. Nilai Risiko yang didapat dan pengendalian yang ada sudah diketahui, keseluruhan tahapan pekerjaan dievaluasi sebagai dasar melakukan tindakan pengendalian berikutnya untuk menurunkan risiko kecelakaan yang ada. 
Tabel 2. Hasil Penilaian Risiko Kecelakaan pengoperasian CC pada PT X Surabaya

\begin{tabular}{|c|c|c|c|c|c|c|c|}
\hline \multirow[b]{2}{*}{$\begin{array}{l}\text { Aktivitas } \\
\text { Pekerjaan }\end{array}$} & \multicolumn{7}{|c|}{ Risiko Kecelakaan } \\
\hline & Tersandung & Terpeleset & Terjatuh & Terjepit & $\begin{array}{c}\text { Kepala } \\
\text { terbentur }\end{array}$ & Tertimpa & $\begin{array}{c}\text { Tersengat } \\
\text { Listrik }\end{array}$ \\
\hline $\begin{array}{l}\text { Menaiki atau } \\
\text { menuruni anak } \\
\text { tangga }\end{array}$ & 12 & 16 & & & & & \\
\hline $\begin{array}{l}\text { Memasuki atau } \\
\text { menuruni lift }\end{array}$ & & & & 10 & & & \\
\hline $\begin{array}{l}\text { Memasuki ruang } \\
\text { operator }\end{array}$ & 12 & & & 9 & & & \\
\hline Pengoperasian CC & & & & & 16 & 2 & 12 \\
\hline
\end{tabular}

Sumber: Nugroho (2016)

Risiko secara umum menurut Joni (2012) didefinisikan sebagai kemungkinan terjadinya peristiwa di luar yang diharapkan. Makin besar kemungkinan rendahnya keuntungan atau bahkan rugi dikatakan makin besar risiko usaha. Penilaian risiko pada aktivitas operator CC didapat 9 risiko kecelakaan. 2 risiko dengan tingkat risiko rendah, 5 risiko dengan tingkat risiko sedang dan 2 risiko dengan tingkat risiko tinggi. Tabel $2 \mathrm{di}$ atas akan menjelaskan identifikasi bahaya dan penilaian risiko pengoperasian CC pada alat CC.

Operator $\mathrm{CC}$ saat naik atau turun tangga, memiliki risiko kecelakaan tersandung dan terpeleset. Tersandung dapat disebabkan dari kurang waspada dan jarak anak tangga yang kurang lebar dapat berisiko tersandung pada saat naik menggunakan anak tangga pada alat CC. Nilai tersandung 12 dari likelihood 4 dan consequences 3. Nilai likelihood 4, karena dalam observasi sering operator menuju cabin operator tidak memakai helm keselamatan. Nilai consequences 3, karena apabila operator tersandung tidak memakai helm keselamatan dapat mengakibatkan cidera terburuk yaitu patah tangan, gegar otak yang memerlukan perawatan medis.

Risiko kecelakaan lain ketika naik atau turun tangga yaitu terpeleset, dengan nilai risiko 16 . Kondisi tangga CC yang berada pada area terbuka dapat kotor terkena debu dari emisi kendaraan, maupun basah terkena air hujan. Akses tangga sebagai akses utama naik menuju alat $\mathrm{CC}$, sehingga nilai likelihood 4. Tingkat kepatuhan penggunaan APD yang kurang, dengan naik ke alat CC tidak menggunakan helm keselamatan sehingga nilai consequences 4 .

Aktivitas pekerjaan yang dilakukan oleh operator selanjutnya naik atau turun menggunakan akses lift. Risiko kecelakaan ada 2 yaitu terjatuh dan terjepit. Terjepit dapat disebabkan tergesa-gesa dalam menutup pintu dan cara menutup pintu yang menyamping. Alat lift merupakan akses utama untuk sampai di atas sehingga nilai likelihood 2. Naik ke ruang operator terjepit saat menutup pintu lift tidak sampai menderita luka yang besar. Luka yang diderita tidak menghambat pekerjaan, sehingga nilai consequences 5 .

Risiko kecelakaan kerja lain yang dapat terjadi yaitu terjatuh dari alat lift. Terjatuh dari lift dapat disebabkan dari kondisi sling yang aus dan tidak pernah dilakukan riksa uji beban. Lift merupakan alat utama untuk menaiki alat CC dan tidak pernah dilakukan riksa uji alat membuat risiko kecelakaan tinggi sehingga nilai likelihood 2. Apabila lift terjatuh ke bawah dapat menimbulkan keparahan kematian, sehingga nilai consequences 1 .

Operator sebelum masuk ruang operator $\mathrm{CC}$, harus melewati tangga dan membuka limit swift. Melewati tangga dan membuka limit swift memiliki risiko kecelakaan tersandung dan terjepit, penyebab kecelakaan tersandung dapat disebabkan dari kurang waspada saat menaiki tangga. Operator harus melewati anak tangga setiap akan memasuki ruang operator, sehingga nilai likelihood ditentukan 3. Melewati anak tangga terkadang operator tidak menggunakan helm keselamatan, sehingga apabila tersandung dan jatuh dapat menimbulkan risiko luka pada tangan maupun kepala. Nilai consequences 4 karena apabila luka pada tangan atau kepala dapat dilakukan pertolongan pertama dengan menggunakan kotak P3K yang ada di ruang operator.

Memasuki ruang operator, operator harus membuka limit swift yang berada sebelum pintu masuk ruangan. Risiko kecelakaan terjepit dapat terjadi, disebabkan dari kurang waspada saat mengangkat. Operator $\mathrm{CC}$ yang hampir tiap hari 
bekerja mengoperasikan alat $\mathrm{CC}$, kemungkinan terjepit sering sehingga nilai likelihood 3. Apabila terjepit memiliki keparahan hingga luka robek pada jari tangan yang harus memerlukan perawatan medis, sehingga nilai consequences 3 .

Pengoperasian alat $\mathrm{CC}$ memiliki risiko kecelakaan kepala terbentur, tertimpa, tersengat listrik. Risiko kepala terbentur dapat disebabkan dari kejut listrik dari alat dan tidak memakai safety belt dalam bekerja. Pengoperasian kecelakaan yang hampir setiap hari serta kepatuhan pemakaian safety belt yang kurang, sehingga nilai likelihood 4. Keparahan apabila mengoperasikan alat terjadi kejut listrik dan dalam kondisi tidak memakai safety belt keparahan terbentur dapat lecet dan akibat membentur besi pembatas kaca, lecet pada kepala dapat ditangani dengan kotak P3K sehingga nilai consequences 4.

Risiko kecelakaan lain yaitu tertimpa. Penyebab kecelakaan dapat disebabkan dari angin kencang saat pengoperasian alat. Angin kencang yang dapat terjadi sewaktu- waktu saat pengoperasian alat sehingga nilai likelihood 2. Angin kencang pada pengoperasian alat dapat menyebabkan alat jatuh ke bawah, apabila jatuh ke bawah mengakibatkan operator jatuh tertimpa alat CC. Apabila operator jatuh tertimpa alat CC keparahan yang diderita yaitu kematian, sehingga nilai consequences 1 .

Pelayanan bongkar muat 24 jam, memungkinkan bekerja dalam kondisi hujan. Memasuki alat CC yang harus menaiki lift dan tangga, dapat membuat operator basah meskipun menggunakan jas hujan. Apabila mengoperasikan alat tanpa mengeringkan tubuh dapat berisiko tersengat listrik dari control panel yang digunakan untuk mengoperasikan alat.

Pengoperasian alat yang hampir setiap hari dan kondisi hujan bisa terjadi sehingga nilai likelihood 4. Keparahan apabila mengoperasikan control panel pada alat CC dalam kondisi tangan basah yang dapat menimbulkan risiko tersengat listrik, keparahan terberat yang dapat dialami yaitu luka bakar sehingga perlu perawatan medis untuk memulihkan kondisi operator.

Keparahan yang diderita yang harus memerlukan perawatan medis untuk penyembuhan, sehingga nilai consequences 3 .

Hasil pengendalian yang dilakukan oleh PT $\mathrm{X}$ pada proses pekerjaan operator CC diketahui paju, pin anchor yang merupakan besi penganjal roda CC serta lubang pengunci roda CC pada alat sudah dilakukan. Pin anchor yang sebelumnya hanya terdapat 4 lubang dengan jarak 250 antar pin, sekarang ditambah menjadi 10 pin pada tiap 100 meter.

Pengendalian administrasi yaitu lisensi K3 pada operator CC, berupa SIO (Surat Ijin Operator) crane. SIO jenis pesawat angkat dengan operator kelas II. Kelas operator disesuaikan dengan kapasitas angkat dari alat angkat dan angkut yang digunakan. Kapasitas angkut pada alat CC di PT X 35 ton.

Pengendalian administrasi terhadap alat, dilakukan dengan pengecekan kondisi keselamatan pada alat CC oleh supervisor sebelum melakukan bongkar muat petikemas. Pengecekan dengan melihat akses keselamatan pada kapal. Emegency drill yang dilakukan setiap 3 bulan sekali kepada seluruh pekerja di dermaga, sirine yang diletakkan pada cabin operator yang terhubung dengan anemometer yang ada di atas alat CC dan safety induction.

Safety induction yang diberikan seputar kondisi lingkungan kerja, persyaratan yang harus dipenuhi memasuki area kerja dan informasi terkait keselamatan kerja di perusahaan. Pada akhir induction dilakukan evaluasi pemahaman peserta terkait materi yang diberikan, dengan memberikan 10 pertanyaan. Tenaga kerja dapat diperbolehkan masuk apabila memenuhi standar nilai yang ditetapkan perusahaan yaitu nilai 75 .

Operator maupun pekerja lain, sudah mengetahui persyaratan dan ketentuan yang ada pada perusahaan. Pemberian induction diberikan oleh deparmenen HSSE (Health safety and security environment), Anemometer yang terpasang pada alat CC digunakan untuk deteksi angin pada area dermaga sebagai upaya pengendalian risiko kecelakaan yang disebabkan oleh angin.

Pengendalian lain yaitu instruksi kerja pengoperasian alat $\mathrm{CC}$ dengan nomor dokumen WI- EQ02- RV03. Namun dari instruksi kerja yang didapat diketahui revisi sudah dilakukan 5 kali dan terakhir direvisi tanggal 4 agustus 2014. Safety sign dan safety alert terkait keselamatan kerja di area dermaga safety sign berisikan himbauan untuk selalu menggunakan APD pada tempat kerja.

Safety alert berupa informasi bahaya maupun kecelakaan yang belum lama terjadi menimpa pekerja, untuk diinformasikan penyebab dan cara kerja yang aman agar bahaya atau kecelakaan yang sama terjadi kembali. Pengendalian APD yaitu helm keselamatan, rompi yang memiliki pendar cahaya, sepatu keselamatan, baju dengan pendar cahaya. Untuk pemakaian APD keseluruhan di pakai, namun untuk pemakaian tingkat kepatuhan masih kurang. 


\section{PEMBAHASAN}

PT X merupakan penyedia jasa bongkar muat petikemas terbesar di Jawa Timur. Pelayanan jasa bongkar muat melibatkan CC (Container Crane) yang dioperasikan oleh operator. Pengoperasian $\mathrm{CC}$ merupakan aktivitas yang penting, karena sebagai alat utama untuk memindahkan petikemas dari kapal ke dermaga maupun sebaliknya. Namun pada pengoperasianya memiliki risiko kecelakaan yang tinggi, diketahui pada tahun 2013 terdapat 57 kecelakaan pengoperasian $\mathrm{CC}$.

Kecelakaan yang terjadi yaitu handling container on deck, handling container under deck, handling hatch, handling containers from land to ship, violation of work procedures, poor maintenance. Sesuai Undang-Undang No. 1 Tahun 1970 Pasal 3 ayat 1 yang mensyaratkan perusahaan mencegah dan mengurangi kecelakaan. Untuk mencegak dan mengurangi kecelakaan pengoperasian CC.

Menurut Tarwaka (2008), pencegahan kecelakaan kerja merupakan upaya untuk mencari penyebab suatu kecelakaan, dengan mengetahui dan mengenal penyebab kecelakaan. Penyebab risiko kecelakaan dipengaruhi empat faktor, yaitu faktor manusia/perilaku kerja, karakteristik/lingkungan kerja, peralatan dan material, dan metode kerja. (Sinaga. 2014). Mengetahui dan mengenal penyebab kecelakaan harus mengetahui aktivitas kerja yang dilakukan. Pencegahan kecelakaan kerja dengan mengetahui proses pekerjaan pada aktivitas operator CC dengan dilakukan identifikasi penyebab kecelakaan.

Teknik yang digunakan mengunakan metode proaktif dengan analisa keselamatan pekerjaan. Setiap tahapan pekerjaan operator CC dilihat risiko kecelakaan dan penyebab kecelakaan. Hasil identifikasi bahaya pada 4 proses pekerjaan pada operator CC diketahui tersandung, terpeleset, terjepit, tertimpa, kepala terbentur, tersengat listrik.

Hasil penilaian risiko didapat 2 risiko kecelakaan yang memiliki tingkat risiko rendah, 5 risiko kecelakaan dengan tingkat risiko sedang dan 2 risiko kecelakaan dengan tingkat risiko tinggi. 2 risiko kecelakaan dengan tingkat risiko tinggi yaitu terjatuh dari lift yang penyebab kecelakaan dari putusnya sling pada lift dan angin kencang pada CC.

Risiko kecelakaan kerja dengan tingkat risiko sedang yaitu tersandung saat menaiki anak tangga, tersandung anak tangga saat memasuki ruang operator, terjepit pintu lift, terjepit limit swift dan tersengat listrik saat mengoperasikan alat CC. Risiko kecelakaan rendah pada aktivitas pekerjaan operator $\mathrm{CC}$ ada 2, yaitu terpeleset dan kepala terbentur. Terpeleset yang disebabkan akses tangga yang licin dan kepala terbentur yang disebabkan tidak memakai safety belt saat mengoperasikan alat CC. Proses selanjutnya setelah melakukan analisa dan evaluasi risiko kecelakaan pada 4 proses pekerjaan yang dilakukan oleh operator $\mathrm{CC}$, dilakukan upaya pengendalian pada setiap proses pekerjaan.

Pengendalian sesuai dengan ISO 31000:2009 dengan urutan eliminasi, substitusi, pengendalian teknik, administrasi dan alat pelindung diri. Pengendalian risiko hendaknya mengikuti risk ratting yang tertinggi yaitu potensi bahaya dengan risiko bahaya urgent, karena karyawan berpotensi mengalami kecelakaan. Zamani (2014). Pengendalian secara keseluruhan pada pengoperasian CC di PT X Surabaya akan di paparkan pada Tabel 3.

Hasil pengendalian yang dilakukan oleh PT X pada proses pekerjaan operator $\mathrm{CC}$ diketahui paju, pin anchor merupakan besi penganjal roda $\mathrm{CC}$ serta lubang pengunci roda $\mathrm{CC}$ pada alat sudah dilakukan. Pin anchor yang sebelumnya hanya terdapat 4 lubang dengan jarak 250 antar pin, sekarang ditambah menjadi 10 pin pada tiap 100 meter.

Penambahan pin anchor sebagai langkah pengendalian teknis yang dilakukan oleh perusahaan, guna mengurangi risiko terjadinya kecelakaan tertimpa akibat angin kencang. Cara kerja dari pin achor yaitu apabila sirine pada alat CC mendeteksi angin melebihi $14 \mathrm{~m} / \mathrm{s}$, operator segera melakukan gantry alat menuju pin achor terdekat, untuk menurunkan anchor pada alat CC.

Anchor merupakan besi berdiameter sekitar 1015 centimeter dengan tinggi sekitar 1 meter, dengan besi horizontal untuk mengangkat atau menurunkan anchor. Paju merupakan besi dengan bentuk segitiga sama sisi, memiliki fungsi pengganjal roda $\mathrm{CC}$ agar tidak berpindah posisi apabila sudah di achor.

Pengendalian administrasi yaitu lisensi K3 pada operator CC, berupa SIO (Surat Ijin Operator) crane. SIO jenis pesawat angkat dengan operator kelas II. Hal ini sesuai dengan Permenaker RI No: Per.09/MEN/VII/2010 yang mensyaratkan pesawat angkat dan angkut harus dilayani oleh operator yang memiliki lisensi K3 berupa SIO sesuai kelas operator. Kelas operator disesuaikan dengan kapasitas angkat dari alat angkat dan angkut yang digunakan. Kapasitas angkut pada alat CC di PT X 35 ton, hal ini sesuai dengan persyaratan klasifikasi 
Tabel 3. Pengendalian Kecelakaan Kerja pada PT X Surabaya

\begin{tabular}{|c|c|c|c|c|}
\hline Jenis & & Upaya Pengendalian & & Keterangan \\
\hline \multirow[t]{2}{*}{ Tersandung } & Teknik & Administrasi & APD & \\
\hline & & $\begin{array}{l}\text { WI, Induction, safety sign, } \\
\text { safety alert, pemberisiah oleh } \\
\text { cleaning service. }\end{array}$ & $\begin{array}{l}\text { Helm, sepatu } \\
\text { keselamatan }\end{array}$ & $\begin{array}{l}\text { Tingkat pematuhan prosedur kerja } \\
\text { dan pemakaian APD kurang. }\end{array}$ \\
\hline \multirow[t]{2}{*}{ Terpeleset } & Teknik & Administrasi & APD & \\
\hline & & $\begin{array}{l}\text { WI, Induction, safety sign, } \\
\text { safety alert }\end{array}$ & $\begin{array}{l}\text { Helm, sepatu } \\
\text { keselamatan }\end{array}$ & $\begin{array}{l}\text { Tingkat pematuhan prosedur kerja } \\
\text { dan pemakaian APD kurang. }\end{array}$ \\
\hline \multirow[t]{2}{*}{ Terjatuh } & Teknik & Administrasi & APD & \\
\hline & & $\begin{array}{l}\text { Perbaikan dan perawatan alat } \\
\text { oleh teknisi. }\end{array}$ & $\begin{array}{l}\text { Helm, sepatu } \\
\text { keselamatan }\end{array}$ & $\begin{array}{l}\text { Perbaikan hanya dilakukan } \\
\text { apabila ada laporan dari operator, } \\
\text { tidak pernah dilakukan load test, } \\
\text { tingkat pemakaian APD kurang. }\end{array}$ \\
\hline \multirow[t]{2}{*}{ Terjepit } & Teknik & Administrasi & APD & \\
\hline & & $\begin{array}{l}\text { Perbaikan dan perawatan alat } \\
\text { oleh teknisi, safety sign }\end{array}$ & $\begin{array}{l}\text { Helm, sepatu } \\
\text { keselamatan }\end{array}$ & $\begin{array}{l}\text { Tingkat pematuhan prosedur kerja } \\
\text { dan pemakaian APD kurang. }\end{array}$ \\
\hline \multirow{2}{*}{$\begin{array}{l}\text { Kepala } \\
\text { terbentur }\end{array}$} & Teknik & Administrasi & APD & \\
\hline & & $\begin{array}{l}\text { SIO operator, WI, Perbaikan } \\
\text { dan perawatan alat oleh } \\
\text { teknisi, safety sign }\end{array}$ & $\begin{array}{l}\text { Helm } \\
\text { keselamatan }\end{array}$ & $\begin{array}{l}\text { Tingkat pematuhan prosedur kerja } \\
\text { dan pemakaian APD kurang }\end{array}$ \\
\hline \multirow[t]{2}{*}{ Tertimpa } & Teknik & Administrasi & APD & \\
\hline & $\begin{array}{l}\text { Paju, penambahan } \\
\text { pin achor tiap } 100 \\
\text { meter }\end{array}$ & $\begin{array}{l}\text { SIO operator, WI, sirine pada } \\
\text { alat, emergency drill }\end{array}$ & $\begin{array}{l}\text { Helm, sepatu } \\
\text { keselamatan }\end{array}$ & $\begin{array}{l}\text { SIO tidak selalu dibawa, sirine } \\
\text { tidak berfungsi, emergency drill } \\
\text { tidak merata ke pekerja }\end{array}$ \\
\hline \multirow{2}{*}{$\begin{array}{l}\text { Tersengat } \\
\text { Listrik }\end{array}$} & Teknik & Administrasi & APD & \\
\hline & & WI, safety sign, & $\begin{array}{l}\text { Jas hujan, } \\
\text { helm dan } \\
\text { sepatu } \\
\text { keselamatan }\end{array}$ & $\begin{array}{l}\text { Perlu penambahan prosedur } \\
\text { dalam kondisi hujan }\end{array}$ \\
\hline
\end{tabular}

Sumber: Nugroho, (2016)

operator kelas II yang dimiliki oleh seluruh operator CC di PT X Surabaya.

Permasalahan yang muncul di lapangan, SIO operator dibawa oleh pihak perusahaan sebagai jaminan bagi operator agar tidak keluar tanpa sepengetahuan perusahaan. Hal ini, kurang sesuai dengan tindakan pencegahan dasar pengoperasian crane. Operator diwajibkan untuk selalu membawa SIO dan buku kerja sesuai dengan Peraturan Menteri Tenaga Kerja dan Transmigrasi Nomor Per.09/Men/ VII/2010 Tentang Operator dan Petugas Pesawat Angkat dan Angkut.
Buku kerja sebagai buku pegangan bagi operator yang memiliki lisensi K3 (SIO), tidak pernah dibawa dan diimplementasikan untuk pengisian. Pengendalian administrasi tidak hanya pada manusia, tetapi juga pada alat. Pengendalian administrasi terhadap alat, dilakukan dengan pengecekan kondisi alat oleh teknisi maintenance.

Pengecekan oleh teknisi maintenance ada pengecekan harian, bulanan dan tahunan. Pengecekan harian dengan mengisi dalily maintenance checklist, pengecekan fungi CC setiap awal shift II (pukul 08.00). Pengecekan bulanan dengan melakukan 
pengecekan oli dan pelumas pada machenary room dan engine room. Pengecekan tahunan dengan melakukan pengecekan dan penggantian sparepart CC yang sudah mengalami kerusakan.

Pengecekan juga dilakukan oleh supervisor terkait kondisi kapal sebelum dilakukan aktivitas bongkar muat. Pengecekan sesuai prosedur kerja yaitu sebelum melakukan bongkar muat petikemas dengan melihat akses keselamatan pada kapal. Pengendalian administratif tidak hanya pengendalian terhadap manusia dan alat, tetapi pengendalian terhadap kondisi lingkungan kerja.

Pengendalian untuk mengurangi risiko kecelakaan yang disebabkan dari lingkungan kerja yaitu emegency drill yang dilakukan setiap 3 bulan sekali kepada seluruh pekerja di dermaga. Pengendalian ini tujuannya memberikan informasi dan prosedur yang harus dilakukan apabila terjadi keadaan darurat. Observasi di lapangan diketahui tidak semua operator pernah mengikuti simulasi, hal ini menunjukkan terkait peserta simulasi tidak mentargetkan merata pada pekerja.

Pengendalian lain yang diberikan terkait risiko kecelakaan yang disebabkan lingkungan kerja yaitu sirine. Sirine diletakkan pada cabin operator yang terhubung dengan anemometer yang ada di atas alat CC. Anemometer akan mendeteksi kecepatan angin yang ada di lingkungan kerja. Apabila, angin yang dideteksi mencapai $14 \mathrm{~m} / \mathrm{s}$, sirine akan berbunyi sebagai tanda keadaan darurat dan pekerjaan harus segera dihentikan. Implementasi di lapangan, sirine pada alat CC kebanyakan sudah tidak berfungsi.

Pengendalian administrative terkait informasi dan pengetahuan $\mathrm{K} 3$ dengan memberikan safety induction yang diberikan oleh safety officer. Materi berisikan persyaratan yang harus dipenuhi memasuki area kerja dan informasi terkait keselamatan kerja di perusahaan. Pada akhir safety induction dilakukan evaluasi pemahaman peserta terkait materi yang diberikan, dengan memberikan 10 pertanyaan.

Pekerja diijinkan memasuki area terbatas, apabila memenuhi standar nilai yang ditetapkan perusahaan yaitu nilai 75. Persyaratan berlaku bagi operator maupun pekerja lain. Pemberian induction yang dilakukan oleh perusahaan merupakan salah satu kewajiban yang sudah ditetapkan pada UndangUndang Keselamatan Kerja No. 1 Tahun 1970 Pasal 9, yang mewajibkan menjelaskan bahaya, pengendalian dan sikap kerja yang aman di tempat kerja.
Pengendalian lain yaitu instruksi kerja pengoperasian alat $\mathrm{CC}$ dengan nomor dokumen WI- EQ02- RV03. Namun dari instruksi kerja yang didapat diketahui revisi sudah dilakukan 5 kali dan terakhir direvisi tanggal 4 agustus 2014 . Sesuai dengan PP 50 Tahun 2012 Tentang SMK3 dalam pelaksanaan rencana $\mathrm{K} 3$ terkait prosedur dan instruksi kerja yang berbunyi "Prosedur dan instruksi kerja harus dilaksanakan dan ditinjau ulang secara berkala jika terjadi perubahan peralatan, proses atau bahan baku yang digunakan oleh personal dengan melibatkan para pelaksanaan yang memiliki kompetensi kerja dalam menggunakan prosedur".

Peninjauan ulang prosedur kerja secara berkala, sesuai dengan pelaksanaan rencana K3 pada PP 50 Tahun 2012 belum sepenuhnya dijalankan. Prosedur kerja pengoperasian $\mathrm{CC}$ belum dilakukan peninjauan ulang kembali, peninjauan ulang prosedur terakhir kali direvisi tahun 2014. Safety sign dan safety alert terkait keselamatan kerja di area dermaga safety sign berisikan himbauan untuk selalu menggunakan APD pada tempat kerja. Safety alert berupa informasi bahaya maupun kecelakaan yang belum lama terjadi menimpa pekerja, untuk di informasikan penyebab dan cara kerja yang aman agar bahaya atau kecelakaan yang sama terjadi kembali. Pengendalian ini merupakan implementasi dari UU No. 1 Tahun 1970 Tentang Keselamatan Kerja pasal 3 ayat 1 yaitu mencegah dan mengurangi kecelakaan.

Alat pelindung diri sebenarnya merupakan pengendalian terakhir apabila empat pengendalian sebelumnya masih tersisa risiko kecelakaan tinggi, namun pada implementasi di lapangan alat pelindung diri sebagai pengendalian utama yang diberikan untuk meminimalisir risiko kecelakaan. Pengendalian dengan pemberian alat pelindung diri diatur sesuai UU No. 1 Tahun 1970 Tentang Keselamatan Kerja pasal 14 butir c yang menyebutkan pengurus diwajibkan menyediakan APD secara cuma-cuma. Pemberian alat pelindung diri pada operator $\mathrm{CC}$ di PT X Surabaya diantaranya alat pelindung kepala, baju kerja dan jaket yang memiliki pendar cahaya dan sepatu keselamatan.

Baju dan jaket kerja yang memiliki pendar cahaya, tujuannya sebagai tanda kepada pekerja lain keberadaan pekerja apabila terjadi penurunan intensitas penglihatan di area kerja. Karena area kerja di dermaga banyak menggunakan kendaraan bergerak, sehingga berisiko untuk terjadinya kecelakaan tertabrak apabila terjadi penurunan intensitas penglihatan. 


\section{SIMPULAN}

Pengoperasian alat CC yang dilakukan operator pada PT X, proses pekerjaan ada 4 yaitu menaiki atau menuruni anak tangga, menaiki atau menuruni lift, memasuki ruang operator, pengoperasian alat CC. Risiko Kecelakaan kerja didapat ada 7 jenis yaitu tersandung, terpeleset, terjatuh, terjepit, kepala terbentur, tertimpa dan tersengat listrik.

Penyebab terjadinya kecelakaan pada aktivitas pekerjaan operator CC yaitu jarak anak tangga yang terlalu dekat dan kondisi anak tangga yang tergenang air, kurang waspada dalam bekerja, putusnya sling dan tidak pernah dilakukan riksa uji pada lift, implementasi prosedur kerja dan pemakaian alat pelindung diri yang masih kurang.

Penilaian risiko yang dilakukan berdasarkan risiko kecelakaan yang didapat, diketahui ada 9 penyebab kecelakaan. Dari 9 penyebab kecelakaan yang memiliki tingkat risiko tinggi 2, tingkat risiko sedang 5 dan 2 tingkat risiko rendah.

Upaya pengendalian pada pengoperasian alat yang dilakukan oleh operator $\mathrm{CC}$ ada 3 jenis pengendalian. Pengendalian Teknis dengan pemberian paju, penambahan pin anchor tiap 100 meter. Pengendalian administrasi yaitu perbaikan dan perawatan oleh teknisi, SIO operator, WI, sirine pada alat, safety sign, emergency drill. Pengendalian APD Helm, sepatu keselamatan, jas hujan.

Pengendalian yang ditetapkan oleh perusahaan sudah sesuai dengan hirarki pengendalian, namun implementasi pengendalian belum sepenuhnya diterapkan oleh perusahaan. Terutama pada upaya pengendalian administrasi terkait prosedur kerja dan APD yang tingkat pematuhan prosedur yang kurang. Tingkat pematuhan penggunaan APD yang kurang selain disebabkan dari kurang lengkap penyediaan dari pihak perusahaan, dapat juga disebabkan dari tenaga kerja itu sendiri. (Bangun. 2015)

Hasil penilaian risiko kecelakaan pada pengoperasian $\mathrm{CC}$, diketahui 2 risiko kecelakaan kerja yang termasuk kategori high risk. Risiko kecelakaan kerja yang termasuk high risk yaitu terjatuh saat menaiki lift dan tertimpa alat CC saat pengoperasian CC. Risiko kecelakaan terjatuh yang dapat disebabkan putusnya sling pada lift, disarankan dilakukan load test dan pengecekan kondisi lift secara berkala. Risiko kecelakaan tertimpa alat CC yang dapat disebabkan oleh kondisi angin, untuk mengurangi risiko kecelakaan perusahaan disarankan melakukan perbaikan fungsi anemometer dan sirine pada tiap CC. Pengendalian administrasi yang dilakukan perusahaan terkait emergency drill, perlu pemerataan partisipasi pada seluruh operator CC.

\section{DAFTAR PUSTAKA}

Bangun. 2015. Risk Assessment Pada Pekerjaan Maintenace di PT X. The Indonesian Journal of Occupational Safety and Health Volume 3 Nomor 2 Juli-Desember 2014: 170-181.

Harjono., Suwandi. 2014. Penilaian Risiko pada Proses Pembuatan Shear Wall Pada Pembangunan Apartemen. The Indonesian Journal of Occupational Safety and Health Volume 1 Nomor 1 Januari-April 2014: 95-106. Webside: http://journal.unair.ac.id/downloadfullpapers-kklk0eec7060c92full.pdf (Sitasi 3 Februari 2014).

HSE Center Indonesia. 2014. Kecelakaan Crane Ambruk Kuningan Jakarta website: http:// hsecenter-id.com/kecelakaan-kerja-craneambruk-kuningan-jakarta/(Sitasi tanggal 25 April 2015).

ISO 31000. 2013. Quality, Enviromental, Occupational Health \& Safety and Supply Chain Risk Management Using ISO 31000:2009. SAI GLOBAL.

Joni. 2012. Risiko Manajemen Proyek. Jurnal Ilmiah Teknik Sipil Volume 16, Nomor 1, Januari 2012. Webside: http://ojs.unhud.ac.id (Sitasi 3 Januari 2016).

Kennedy. 2009. Southampton docks' crane collapse raises questions over how it happened again webside: http://www.dailyecho.co.uk/ news/4491208.Questions_asked_over_port crane_collapse/(Sitasi tanggal 30 April 2015)

Nugroho. 2016. Penilaian Risiko Kecelakaan Kerja Pada Pekerja Bongkar Muat Petikemas di PT X Surabaya. Skripsi. Surabaya: Fakultas Kesehatan Masyarakat Universitas Airlangga.

Peraturan Menteri Tenaga Kerja dan Transmigrasi Nomor Per 05/Men/1985 Tentang Pesawat Angkat dan Angkut. Jakarta: Depnakertrans.

Peraturan Menteri Tenaga Kerja dan Transmigrasi Nomor Per.09/Men/VII/2010 Tentang Operator dan Petugas Pesawat Angkat dan Angkut. Jakarta: Depnakertrans.

Peraturan Pemerintah Republik Indonesia Nomor 50 Tahun 2012 Tentang Penerapan Sistem Manajemen Keselamatan dan Kesehatan Kerja. Jakarta: Depnakertans.

Pusat Data Informasi dan Ketenagakerjaan (Pusdatinaker). 2015. Tipe Kecelakaan 
KerjaTriwulan IV Tahun 2014. webside:Pusdatinaker.balitfo.depnakertras.go.id (Sitasi tanggal 23 April 2015

Sinaga., Bintang., Adi. 2014. Identifikasi dan Analisis Risiko Kecelakaan dengan Metode FMEA(Failure Mode and Effect Analysis) dan FTA (Fault Tree Analysis) di Proyek Jalan Tol SurabayaMojokerto. Jurnal Teknik Pomits Volume 1, Nomor 1 (2014). Webside: http://digilib.its.ac.id/ public/ITS-paper-38421-3112105056-paper.pdf (Sitasi 3 Februari 2016).

Suma'mur, 2009. Higiene Perusahaan dan Keselamatan Kerja (Hiperkes). Jakarta: CV Haji Masagung.

Tarwaka, 2008. Keselamatan dan Kesehatan Kerja. Manajemen Implementasi K3 di tempat kerja, Surakarta: Harapan Press.
Undang-Undang No. 1 Tahun 1970 Tentang Keselamatan.

Wahyudiyanta. 2012. Dua Kuli Pelabuhan Tewas Tertimpa Crane Kapal webside: http://news.detik. com/surabaya/read/2012/11/27/021137/2102109 /466/dua-kuli-pelabuhan-tewas-tertimpa-cranekapal (Sitasi tanggal 24 April 2015)

Zamani. 2014. Identifikasi Bahaya Kecelakaan Unit Spinning 1 menggunakan metode HIRARC di PT. Sinar Pantji Djaja. Unnes Journal of Public Health Volume 3 Nomor 1 2014. Webside: http:// journal.unnes.ac.id (Sitasi, 3 Februari 2016) 